\title{
Human adipose stem cell and ASC-derived cardiac progenitor cellular therapy improves outcomes in a murine model of myocardial infarction
}

This article was published in the following Dove Press journal:

Stem Cells and Cloning:Advances and Applications

29 October 2015

Number of times this article has been viewed

\author{
Philip MC Davy' \\ Kevin D Lye $\mathrm{L}^{2,3}$ \\ Juanita Mathews' \\ Jesse B Owens' \\ Alice Y Chow' \\ Livingston Wong ${ }^{2}$ \\ Stefan Moisyadi \\ Richard C Allsopp' \\ 'Institute for Biogenesis Research, \\ ${ }^{2}$ John A. Burns School of Medicine, \\ University of Hawaii at Mānoa, ${ }^{3}$ Tissue \\ Genesis, Inc., Honolulu, HI, USA
}

Correspondence: Philip MC Davy Institute for Biogenesis Research, John A. Burns School of Medicine, University of Hawai'i at Mānoa, 65I Ilalo Street, Biosciences Building Room I67E, Honolulu, HI 96813, USA Tel +l 808692 I749

Fax +l 8086921962

Email pdavy@hawaii.edu
Background: Adipose tissue is an abundant and potent source of adult stem cells for transplant therapy. In this study, we present our findings on the potential application of adipose-derived stem cells (ASCs) as well as induced cardiac-like progenitors (iCPs) derived from ASCs for the treatment of myocardial infarction.

Methods and results: Human bone marrow (BM)-derived stem cells, ASCs, and iCPs generated from ASCs using three defined cardiac lineage transcription factors were assessed in an immune-compromised mouse myocardial infarction model. Analysis of iCP prior to transplant confirmed changes in gene and protein expression consistent with a cardiac phenotype. Endpoint analysis was performed 1 month posttransplant. Significantly increased endpoint fractional shortening, as well as reduction in the infarct area at risk, was observed in recipients of iCPs as compared to the other recipient cohorts. Both recipients of iCPs and ASCs presented higher myocardial capillary densities than either recipients of BM-derived stem cells or the control cohort. Furthermore, mice receiving iCPs had a significantly higher cardiac retention of transplanted cells than all other groups.

Conclusion: Overall, iCPs generated from ASCs outperform BM-derived stem cells and ASCs in facilitating recovery from induced myocardial infarction in mice.

Keywords: adipose stem cells, myocardial infarction, cellular reprogramming, cellular therapy, piggyBac, induced cardiac-like progenitors

\section{Introduction}

Adipose tissue, like many human tissues, has been found to contain a population of progenitor cells that act as a reservoir for post-developmental cellular replenishment throughout adult life. The composite cells of adipose tissue were initially separated from mice in the $1960 \mathrm{~s}^{1}$ during studies of fat metabolism. This set up the basic methodology of adipose cell isolation; fat tissue is mechanically and enzymatically dissociated before separation of adipocytes from the stromal vascular fraction (SVF) by centrifugation. The identification of fibroblast-like adipocyte precursor cells, ${ }^{2}$ combined with adipose hyperplasia, ${ }^{3}$ and the high degree of surface phenotype similarity between cultured adherent SVF cells and bone marrow (BM) mesenchymal stem cells (MSCs) ${ }^{4}$ led to application of the nomenclature adipose-derived stem cells, or ASC. ASCs easily differentiate into mesoderm cell types (adipocytes, myocytes, chondrocytes, and osteoblasts) ${ }^{4}$ and are plastic enough to form certain endoderm and ectoderm cell types as well. ${ }^{5,6}$ Their ease of acquisition from liposuction aspirate, active immune suppression, ${ }^{7}$ and aforementioned plasticity make ASCs an attractive option for therapeutic applications. 
Ischemic heart disease, the most common cause of myocardial infarction, is the leading cause of death by disease worldwide. BM cell therapy for myocardial infarction has been extensively explored in both animal models ${ }^{8}$ and clinical trials $^{9}$ for more than a decade. The outcome of this research indicates that the administration of BM mononuclear cells into the heart following an infarction ameliorates the detrimental remodeling of the myocardium through paracrine signaling, rather than cellular replacement by differentiation of progenitor cells. ${ }^{10} \mathrm{BM}$ myocardial transplantation resulted in retention of cardiac output, as measured by left ventricular ejection fraction (LVEF) and left ventricular end systolic volume, and a reduction of future incidence of infarction when autologous BM therapies were applied in clinical trials. ${ }^{9}$ A key observation of interventive therapies to treat myocardial infarction is the restoration of circulation, illustrating the vital role for revascularization in treatment. We have previously demonstrated that the hematopoietic stem cell (HSC) fraction of the BM is critical to myocardial remodeling. ${ }^{11}$ In particular, we observed an increase in the relative amount of HSCs within BM transplanted into the myocardium led to reduced fibrotic remodeling. ${ }^{11}$ Also, as confirmed by others, ${ }^{12,13}$ revascularization of the impacted area of myocardium was directly related to the quantity of HSC present in BM therapies. In multiple animal models, ASCs have demonstrated similar properties for cellular therapy of myocardial infarction. ${ }^{14-18}$ ASCs have also been shown to have specific paracrine signaling that is antiapoptotic and proangiogenic ${ }^{19}$ with a greater potential for the latter than BM-derived MSCs..$^{20}$ Although intramyocardial ASC transplantation has lagged behind $\mathrm{BM}$ cell treatments in progression to clinical trials, early results of the APOLLO trial showed great promise for their clinical application. ${ }^{21}$

Transposon-mediated gene transfer into target cells offers several advantages over plasmid and viral methods. Most important of these is the nonrandom integration of the genes of interest into the host genome. ${ }^{22}$ Unlike retroviral integration into the host genome, piggyBac-mediated integration is reversible, as demonstrated by the generation of induced pluripotent stem cells (iPSCs) followed by seamless excision of the reprogramming factors. ${ }^{23}$ Transposon vectors are useful for difficult-to-transfect cells,${ }^{24}$ allowing efficient expression of multiple genes of interest with a single-transfection event. piggyBac vectors stably integrate and efficiently insert their cargo under a variety of complex conditions, as demonstrated by the generation of transgenic pigs by cytoplasmic injection with the piggyBac-based vector $\mathrm{p} m$ GENIE- $3 .{ }^{25}$
Until recently, stem cell dogma held that differentiation from stem cells to somatic phenotypes was irreversible in mammalian cells and that multipotent adult stem cells were limited to differentiation into specific subsets of somatic cells. That was overturned by the reprogramming of terminally differentiated fibroblasts to their embryonic-like origin with the induced expression of just four genes. ${ }^{26}$ The same methodology that determined the minimal number of defined factors necessary for reprogramming somatic cells to iPSCs has now been applied to a cardiomyocyte endpoint. ${ }^{27-29}$ Led by early evidence for the importance of two of these factors, ${ }^{27}$ it was discovered that in mice only three transcription factorsGata4, Mef2c, and Tbx5 (GMT)-were necessary to reprogram murine neonatal cardiac fibroblasts to a cardiac myocyte phenotype without a stem cell intermediary phase. ${ }^{28,29}$

In the present study, we direct the differentiation of adult human adipose stem cells toward the cardiac lineage by transposon-mediated genome integration of cardiac transcription factors. In a mouse model of myocardial infarction, we show that the resulting iCPs enhance functional outcomes, and that these iCPs demonstrate greater retention in the host myocardium than transplanted ASCs or BM-derived stem cells.

\section{Materials and methods}

\section{Animals}

NOD.CB17-Prkdcscid/J Severe Combined Immune Deficient mice (Jackson Laboratory, Bar Harbor, ME, USA) were housed in aseptic caging in accordance with the guidelines of the Laboratory Animal Services at the University of Hawaii and the Committee on Care and Use of Laboratory Animals of the Institute of Laboratory Resources National Research Council (DHEW publication 80-23, revised in 1985).

\section{Adipose-derived stem cells}

Human ASCs utilized for this study were acquired from Tissue Genesis, Inc. (Honolulu, HI, USA) who processed fresh lipoaspirate with their Icellator Cell Isolation System. The 1 hour process was performed on lipoaspirate within 24 hours of collection, and the SVF product delivered for application within another hour, at which time the mean cell viability was $\sim 80 \%$ with minimal variation between specimens. For transplantation, the SVF was pelleted and resuspended in phosphate buffered saline (PBS) at $2.5 \times 10^{5}$ cells per $30 \mu \mathrm{L}$ for delivery by intracardiac injection with a 30 -gauge insulin syringe. Transplantations into infarcted hearts occurred within 4 hours of delivery from Tissue Genesis, Inc. Adherent cells from the SVF were cultured in Mesencult MSC Medium (Stemcell Technologies, Vancouver, BC, Canada) in Falcon 
six-well tissue culture plates (Corning Incorporated, Corning, NY, USA) and passaged at a 1:2 ratio. To assess the ASC content of the SVF, the profiles of cell surface markers CD31, CD45, CD90, and CD105 (eBiosciences, San Diego, CA, USA; 12-0319-41, 12-9459-41, 11-0909-41, and 17-1057-41, respectively) were characterized by fluorescence-activated cell sorting (FACS) analysis using a FACSAria ${ }^{\mathrm{TM}}$ III (BD Biosciences, San Jose, CA, USA), with ASCs designated as the phenotype $\mathrm{CD} 31^{-} \mathrm{CD} 45^{-} \mathrm{CD} 90^{+} \mathrm{CD} 105^{+}$as previously reported. ${ }^{4}$ The ASCs content of the SVF was found to be $3.1 \% \mathrm{CD} 90^{+} \mathrm{CD} 105^{+} \mathrm{CD} 31^{\text {neg }} \mathrm{CD} 45^{\text {neg }}$, which correlates to $80 \%$ confluency after 3 days in culture when the SVF is plated at a density of $1 \times 10^{5}$ cells $/ \mathrm{cm}^{2}$.

\section{Construction of a three-factor piggyBac programming vector (pmGENIE-3-GMT)}

Genes for human TBOX5, GATA4, and MEF2C were purchased from GeneCopoeia as vectors EX-Z5705-M02, EX-F0146-M02, and EX-Z1133-M02, respectively. Vector EX-Z1133-M02 was cut with NotI and an IRES GFP was In-Fused (Clontech, Mountain View, CA, USA) in at that site, making a TBOX5 IRES GFP in the resulting vector EX-Z1133-M02-GFP. Invitrogen's Gateway multisite control vectors pENTR L1-pLac-lacZalpha-L4, pENTR R4-pLac-Spect-R3, and pENTR L3-pLac-Tet-L2 were used to construct the appropriate pENTR vectors containing TBOX5, GATA4, and MEF2C, respectively, using In-Fusion primers to amplify and add flanking AseI sites to the portion of the pENTR vectors with the appropriate LR sites, origin of replication, and kanamycin resistance gene. These PCR products were then In-Fused with AseI cut fragments containing the genes of interest from EX-Z1133-M02-GFP, EX-Z5705-M02, and EX-F0146-M02, resulting in pENTR TBOX5 GFP L1-L4, pENTR GATA4 R4-R3, and pENTR MEF2c L3-L2. MultiSite Gateway cloning was then used to combine all three genes of interest into the destination vector pmGENIE-3, resulting in pmGENIE-3-GMT.

\section{ASC programming strategy}

The piggyBac transposon vector is a nonviral vector capable of inserting large cassettes of DNA into the human genome, ${ }^{30}$ making it very suitable for the delivery of all three components of GMT into ASCs for programming. As such, this vector was utilized to construct an all-in-one expression construct (pmGENIE-3-GMT) to allow delivery and simultaneous expression of the programming factors. Human ASCs were nucleofected at $\sim 70 \%$ confluency earlier than passage 6 with $2 \mu \mathrm{g}$ p $m$ GENIE3-GMT per $4 \times 10^{5}$ cells using Nucleofector II
(Lonza, Basel, Switzerland) and HCAEC Nucleofector Kit with program S05. Immediately following transfection, cells were transitioned to culture in Cardiac Myocyte Medium (ScienCell Research Laboratories, Carlsbad, CA, USA). Forty-eight hours after transfection, GFP-positive cells were separated by FACS using a FACSAria ${ }^{\mathrm{TM}}$ III (BD Biosciences) and returned to culture. At 14 days post-transfection, cells were collected by trypsin dissociation for analysis or transplantation (Figure 1). The therapeutic goal we envision is point-of-care application that utilizes the anti-inflammatory and proangiogenic properties of ASC with reparative cardiac programmed cells. Thus, iCP cells were transplanted at a 2:1 ratio with ASC for in vivo assessment of their therapeutic potential.

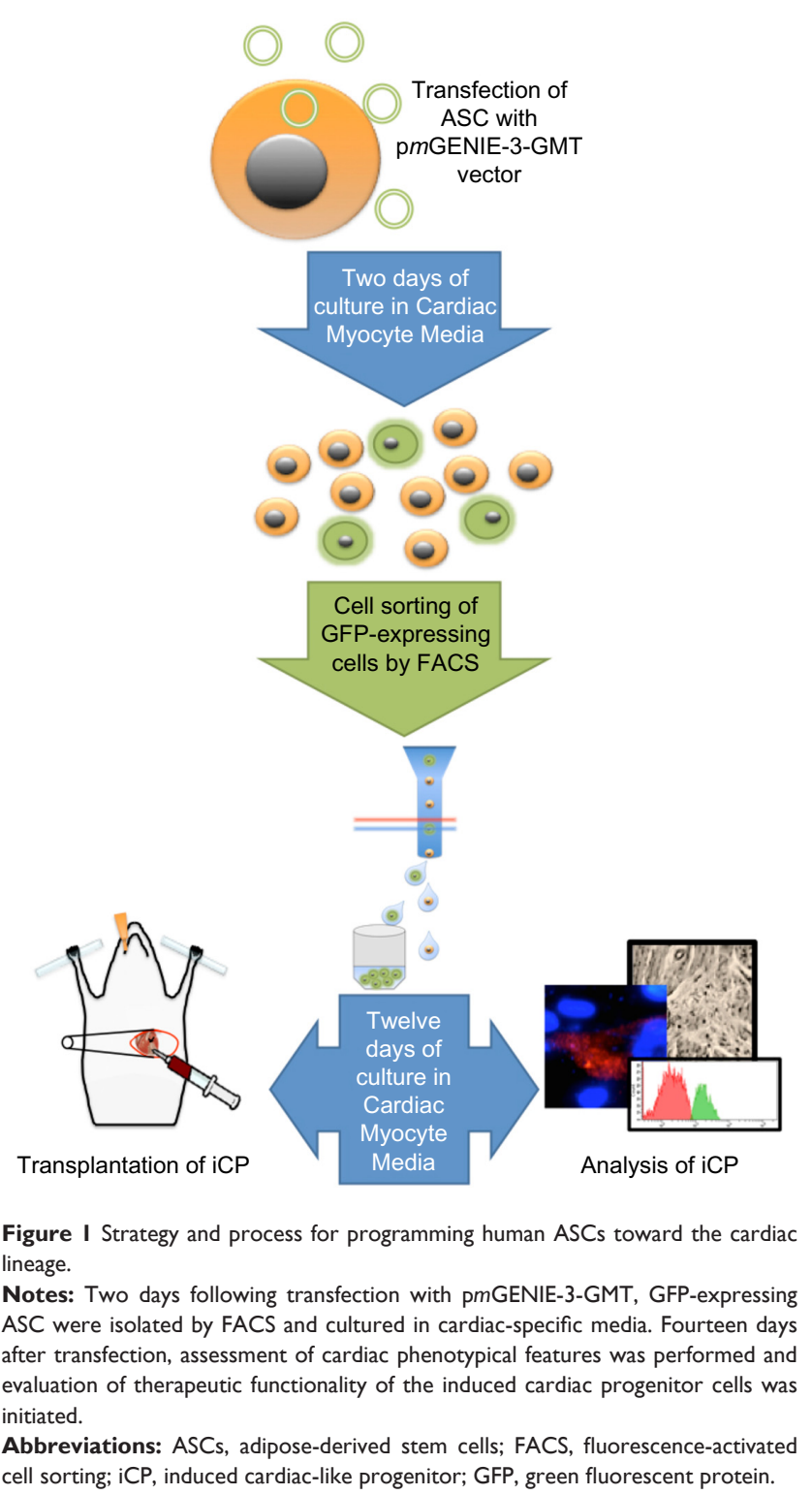




\section{Immunocytochemistry}

Prior to fixation, cells were dissociated from tissue culture plates with $0.05 \%$ trypsin, loaded onto $22 \mathrm{~mm}^{2}$ glass cover slips precoated with laminin (BD Biosciences), and incubated overnight at $37^{\circ} \mathrm{C}$. Twenty-four hours later, culture media was removed and the cells washed once with PBS. Methanol fixation at $-20^{\circ} \mathrm{C}$ for 10 minutes was followed by washing with PBS. Immunocytochemistry was performed at room temperature; briefly, 0.5\% fish skin gelatin (FSG) (Sigma-Aldrich, St Louis, MO, USA) in PBS was used as a blocking reagent for 1 hour, primary antibody in $0.05 \%$ FSG was applied for 30 minutes, cover slips were washed twice with PBS, and secondary antibody in $0.05 \%$ FSG was applied for 30 minutes. Cover slips were mounted on glass slides in mounting media containing DAPI (Dako Denmark A/S, Glostrup, Denmark). Primary $\alpha$-actinin (ab209776) and Troponin T (ab8295), and secondary Dylight 488 (ab96891) and 594 (ab96877) antibodies (Abcam, Cambridge, MA, USA) were used at 1:800 dilution.

\section{Quantitative PCR}

Quantitative real-time PCR was used to assess the expression of cardiac-specific genes in iCPs 14 days after transfection. iCPs from three separate transfection events and untreated ASCs cultured for the same period in Cardiac Myocyte Medium were collected by trypsin dissociation and washing in PBS prior to storage in RNAlater (Life Technologies, Carlsbad, CA, USA) at $4^{\circ} \mathrm{C}$. Total RNA was collected from RNAlater-stored samples using an RNAeasy kit (Qiagen, Valencia, CA, USA). Total RNA from human heart tissue was purchased (Ambion, Thermo Fisher Scientific, Waltham, MA, USA) to provide baseline expression positive control values. $1 \mu \mathrm{g}$ of RNA was used to construct cDNA with an iScript cDNA Synthesis Kit (Bio-Rad, Hercules, CA, USA). $50 \mathrm{ng}$ of cDNA was used in triplicate $25 \mu \mathrm{L}$ reactions with iQ SYBR Green Supermix (Bio-Rad) on a MyiQ Single-Color Real-Time PCR System (Bio-Rad). Primers for genes with no expression in ASC were analyzed such as $\mathrm{Nkx2}-5$, Troponin $\mathrm{T}$ type 2, $\alpha$-actinin 2, $\alpha$-Myosin Heavy Chain, Islet 1, Connexin 43, Myosin Light Chain-2v, Myosin Light Chain-2a, PECAM 1 , EGFP, and GAPDH. Data are presented as $\log _{2}$-fold change $\left(2^{-\Delta \Delta C t}\right)$ in expression relative to total human heart RNA.

\section{Collection and enrichment of human bone marrow}

BM samples were obtained from deceased anonymous donors in collaboration with the Transplant Institute of the Pacific (Hawaii Medical Center East; Honolulu, HI, USA). The Institutional Review Board for the University of Hawai'i cleared this study from oversight because samples were obtained with the informed written consent of a direct family member. Mononuclear cells were prepared from thawed BM aspirates by following the manufacturer's protocol for density gradient separation using GE Ficoll-Paque PREMIUM. CD34 ${ }^{+}$in $^{\text {neg }}$ cells were enriched by magnetic activated cell sorting with the Lineage Cell Depletion Kit (Miltenyi Biotec, San Diego, CA, USA).

\section{Infarction and cell transplantation}

Left anterior descending (LAD) coronary artery ligation was performed in mice to produce an acute myocardial infarction. Briefly, mice were anesthetized with 5\% isoflurane and nonsurgically intubated before transfer to artificial ventilation using a small-rodent ventilator (Harvard Apparatus, Holliston, MA, USA). Anesthesia was maintained throughout surgery using $1.5 \%$ isoflurane provided through the ventilator. A thoracotomy was performed through the fourth left intercostal space, the pericardium was separated and opened, and the heart exposed. The LAD was identified using the left atrium and branches of the left cardiac vein as anatomic landmarks. An 8-0 silk suture was passed under the LAD and knotted to induce ligation, which was visually verified by paling of the myocardium.

Approximately 1 minute after LAD ligation, $2.5 \times 10^{5}$ cells suspended in $30 \mu \mathrm{L}$ PBS, or an equal volume of sterile PBS, were injected using 30 -gauge insulin syringes into three equidistant peri-infarct positions around the infarcted area. The chest cavity was closed in layers using 6-0 silk sutures, and the animals were recovered from anesthesia. Upon resumption of autonomous respiration, animals were removed from ventilation and placed in a bleach sterilized, heated recovery chamber supplied with oxygen until resumption of normal behavior. Average mortality rates were $\sim 30 \%$; excessive blood loss and sudden cardiac arrest were the primary complications. Post-recovery mortality from infarct complications was less than $10 \%$. The University of Hawai' ${ }^{\prime}$ Institutional Animal Care and Use Committee approved this study, and these animal procedures were carried out under protocol number 09-673, all available precautions were taken to minimize animal suffering.

\section{Echocardiography}

Short-axis M-mode echocardiograph analysis of heart function was performed on unanesthetized mice at -1 (baseline) and 30 days following the procedure using a Vevo2100 ultrasound device (FUJIFILM Visual Sonics, Inc., Toronto, ON, Canada) with an $18 \mathrm{MHz}$ transducer. At each timepoint, ten separate heartbeats per mouse were analyzed using the software on the Vevo2100 to determine LVEF and left ventricular fractional shortening (LVFS). 


\section{Histology}

Thirty days after LAD ligation, all mice were sacrificed, and hearts were retrieved for histochemical analysis. Briefly, the hearts were arrested in $5.4 \mathrm{mM} \mathrm{KCl}$ at $4^{\circ} \mathrm{C}$ before 6 hours of fixation within fresh $4 \%$ paraformaldehyde. Prior to paraffin embedding, hearts were visualized for macroscopic indications of the infarct and bisected with the lower ventricular section being embedded. Ten successive $5 \mu \mathrm{m}$ sections were collected on five slides to obtain sections from the center of the infarction. Following staining, images were acquired using an Olympus BX41 microscope and Pictureframe v2.3 software (Optronics, Goleta, CA, USA), then quantified and analyzed using ImageJ (version $1.44 \mathrm{n}$ ).

Morphometric analysis of collagen deposition using Masson's Trichrome (Sigma-Aldrich) staining to assess infarct size provided the epicardial circumference of scarred left ventricle, percentage of viable myocardium, and area at risk of the left ventricle (area of LV between the two edges of the infarct scar). ${ }^{31}$

Revascularization of the peri-infarct zone was assessed by quantification of capillary density by a sample-blinded observer utilizing 3,3'-diaminobenzidine (Dako) visualization of endothelial-specific Isolectin B4 staining (Invitrogen, Thermo Fisher Scientific).

Prior to transplantation, some preparations of cells were labeled with the membrane dye CM-DiI (Thermo Fisher Scientific) following the manufacturer's instructions. Quantification of labeled cells to determine the persistence of transplanted cells within endpoint heart sections was performed following image acquisition using a Texas Red filter.

\section{Statistical analysis}

Comparisons of data from all cohorts were conducted using Student's $t$-test; $P$-values $\leq 0.05$ were considered significant. The initial number of mice assigned to each group prior to surgery was 12 ; due to losses the in vivo echocardiography and histological analyses $n$ values for each group are as follows: control (CTL) $n=5$; CD34 ${ }^{+} \operatorname{Lin}^{\text {neg }} \mathrm{BM}$ cells (HSC) $n=8$; ASCs $n=7$; iCPs $n=9$.

\section{Results}

\section{Strategy for the programming of multipotent ASCs to the cardiac lineage}

The GMT transcription factor combination has previously been shown to directly reprogram mouse fibroblasts to a cardiac phenotype. ${ }^{29}$ Subsequently, it was determined that the addition of the cardiac transcription factor HAND2 to this combination (GHMT) increased the efficiency of reprogramming of adult murine fibroblasts to a cardiac phenotype. ${ }^{32}$ Human cardiac and noncardiac adult fibroblasts have presented a greater challenge. The addition of either the two microRNAs miR-1 and miR-133 to GHMT, ${ }^{33}$ or GMT plus Mesp1 and either Myocd, ${ }^{34}$ or ESRRG ${ }^{35}$ were required to generate significant numbers of reprogrammed cells with a cardiac phenotype. The terminally differentiated nature of human adult fibroblasts may limit the success of reprogramming with GMT alone; Nam et al compared the reprogramming efficiency of various combinations of transcription factors on neonatal human foreskin fibroblasts and adult human cardiac or dermal fibroblasts and found the efficiency to be higher for the neonatal fibroblasts in every circumstance. ${ }^{33}$

In this study, we assessed the potential of GMT to reprogram ASCs, a multipotent and clinically redundant adult stem cell, to the cardiac phenotype. By combining the rapid acquisition of ASCs using the Icellator system and the nonviral, single-transfection capacity of p $m$ GENIE-3-GMT, we derived a strategy that offers the possibility of a pointof-care application of autologous ASCs programmed to the cardiac phenotype at the acute phase of AMI. To assess the therapeutic potential of the programmed ASCs, an in vivo comparison of equal numbers of BM-derived stem cells and unmodified ASCs in the mouse model of myocardial ischemia was performed (Figure 1).

\section{ASCs are efficiently reprogrammed to cardiac progenitors after nucleofection with pmGENIE-3-GMT}

A transposase-mediated delivery system, $\mathrm{p} m$ GENIE-3-GMT ( $18 \mathrm{kbp}$ ), was constructed to deliver the programming factors, including a downstream IRES-GFP reporter to facilitate rapid detection of transfected cells (Figure 2). Using nucleofection to deliver to ASCs, $\sim 25 \%$ of cells were observed to express GFP at 48 hours (Figure 3A). At this point, GFP-positive cells were purified using FACS and returned to culture for analysis (Figure 3B).

Fourteen days after transfection with p $m$ GENIE-3-GMT, cells from three independent transfection events showed marked upregulation of the cardiac-progenitor gene Nkx2.5, which was not seen in ASC cultured in the same conditions without programming. Islet 1 , also a marker for cardiac development, was observed in ASC cultured in Cardiac Myocyte Media (CMM) and remained highly expressed in two of the three iCP lines at 14 days postprogramming. The endothelial marker PECAM-1 was weakly expressed in ASC CMM relative to the human heart and its expression was consistently upregulated in iCP. Connexin 43 , an gap-junction protein important to the heart, was observed to have variable expression, which was close to human heart in two of 


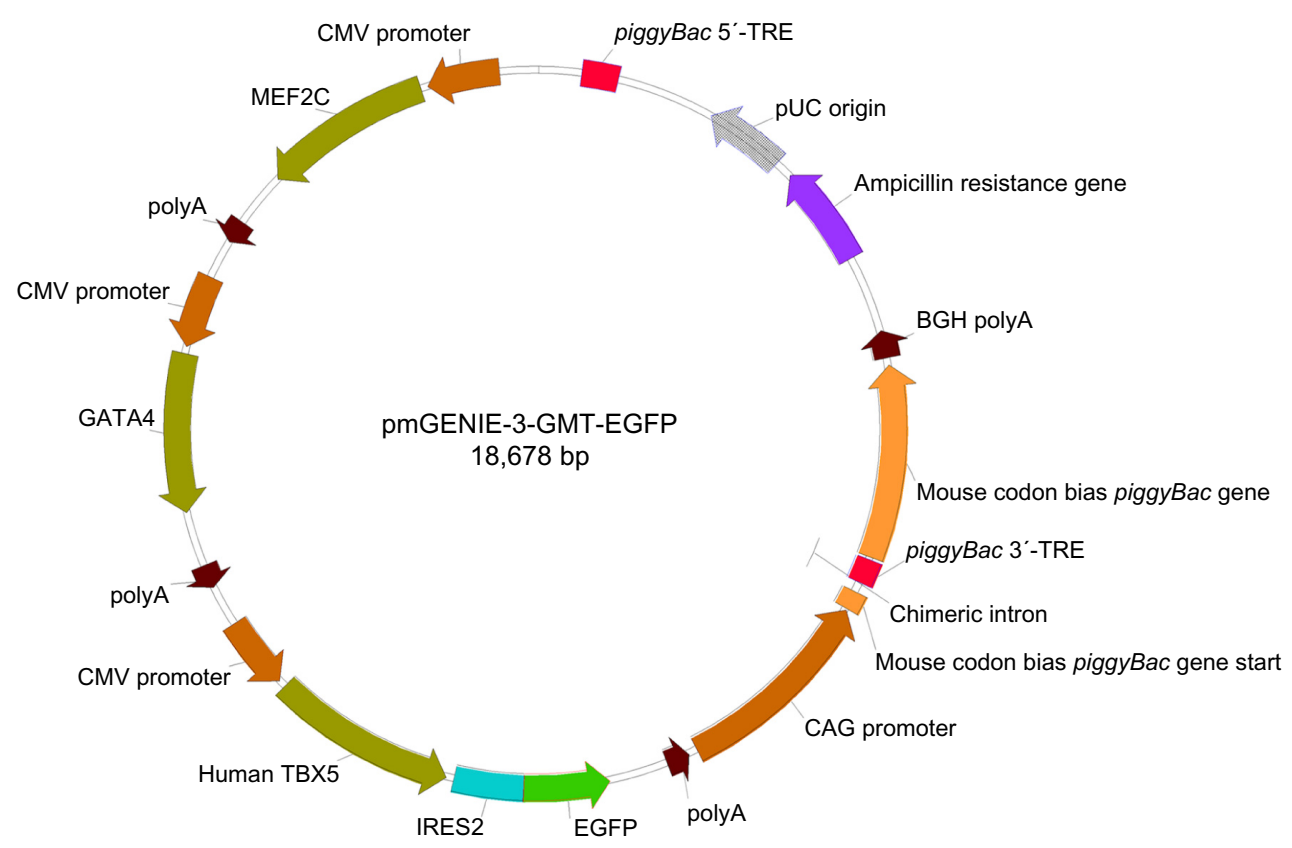

Figure 2 Map of the pmGENIE-3-GMT piggyBac vector constructed for programming ASCs toward the cardiac lineage.

Notes: The cassette containing GATA4, MEF2C, and TBX5 cDNAs (dark green) is flanked by piggyBac transposon insertion sites at the $3^{\prime}$ and $5^{\prime}$ ends to facilitate integration into the host genome. Each gene is flanked by a $5^{\prime}$ cytomegalovirus (CMV) promotor region and a $3^{\prime}$ polyA tail, and EGFP is interlinked to the $3^{\prime}$ end of TBX5 by an IRES sequence to ensure construct-specific expression of the reporter.

Abbreviations: GMT, GATA4, MEF2C, and TBX5; ASCs, adipose-derived stem cells; IRES, internal ribosome entry site; EGFP, enhanced green fluorescent protein; CAG, CMV early enhancer/chicken beta actin; pUC, plasmid bacterial origin of replication.

A

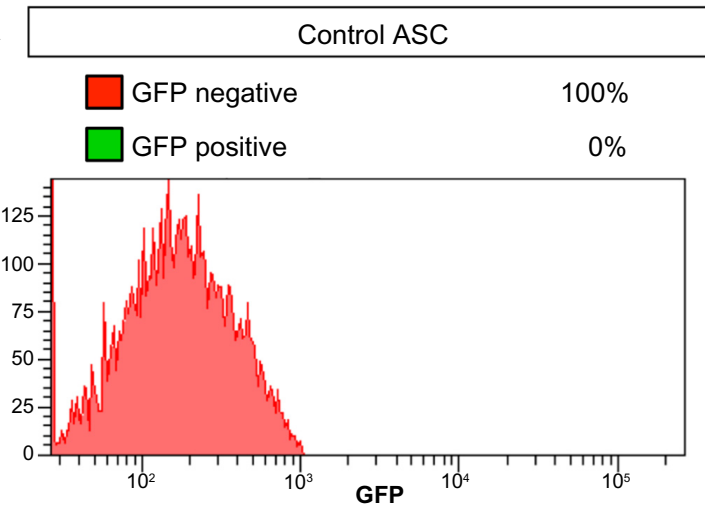

B

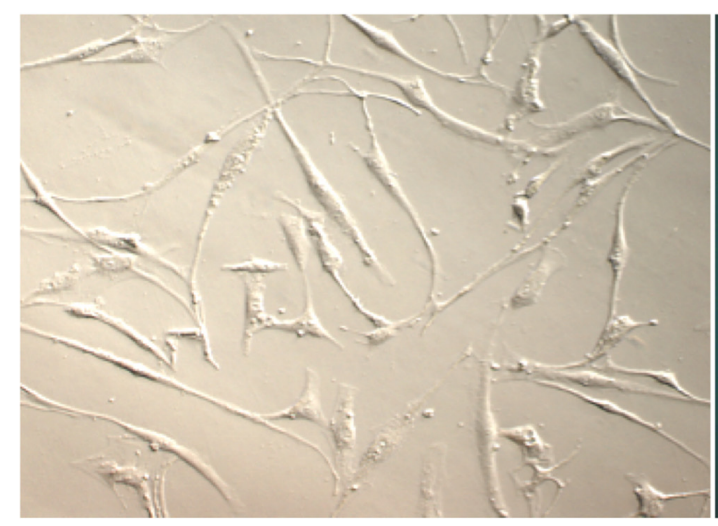

\begin{tabular}{|cc|}
\hline \multicolumn{2}{|c|}{ GMT transfected ASC } \\
\hline GFP negative & $74.5 \%$ \\
$\square$ GFP positive & $25.5 \%$
\end{tabular}
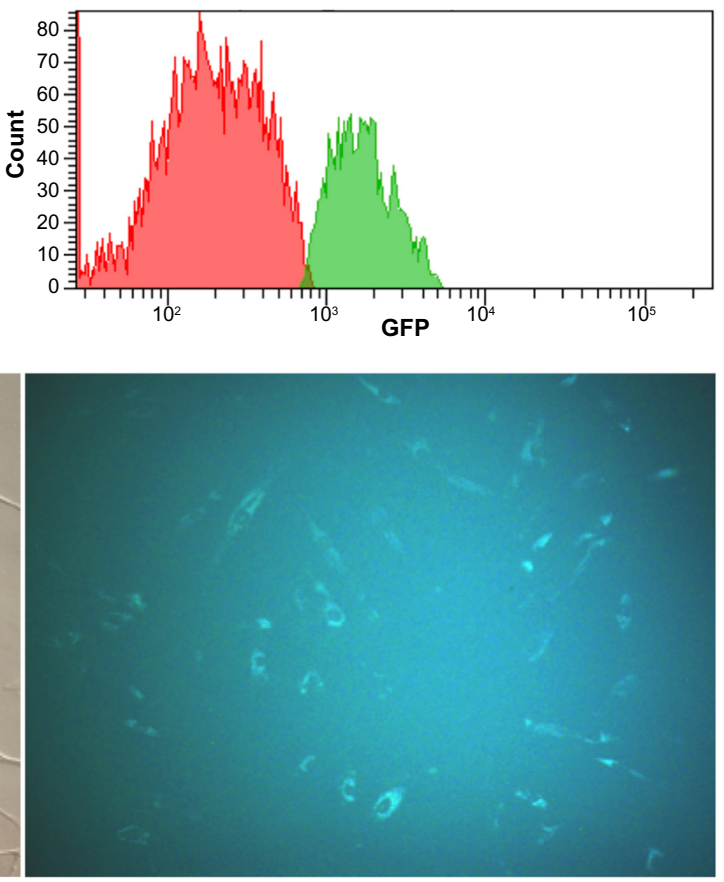

Figure 3 Analysis of transfection efficiency of ASCs with pmGENIE-3-GMT.

Notes: FACS analysis was performed on ASCs 48 hours postnucleofection (A). Bright field (left) and fluorescent (right) microscopy images of GMT-expressing cells I day after FACS sorting of GFP-positive cells (B).

Abbreviations: ASCs, adipose-derived stem cells; GMT, GATA4, MEF2C, and TBX5; FACS, fluorescence-activated cell sorting; GFP, green fluorescent protein. 
the three iCP lines. Markers of mature cardiac development were not found in ASC culture in CMM but were consistently highly expressed in iCP. Troponin T (type 2), MLC2v, and MLC2a expression levels were observed to be higher in all iCP lines than in total human heart RNA. Alpha actinin 2 was also upregulated in iCP, but not as consistently as other mature cardiac markers (Figure 4). Transcript levels of EGFP were analyzed in the RNA collected from the three iCP lines (Figure S1). Importantly, no expression of cardiac-specific genes has been detected in untransfected ASCs or HSCs. iCPs were observed contracting in a frequency-dependent manner ${ }^{36}$ under electrical stimulation (Video S1).

Immunohistochemical analysis of cardiac-specific proteins Troponin $\mathrm{T}$ and $\alpha$-actinin showed expression in $>90 \%$ of reprogrammed cells 14 days after transfection. In contrast, ASCs not transfected with p $m$ GENIE-3-GMT but maintained in the same culture conditions for the same period did not show any expression of these cardiac proteins (Figure 5A). Sarcomeric banding of $\alpha$-actinin was observed in reprogrammed cells (iCPs) (Figure 5B). These findings represent an efficiency of programming of p $m$ GENIE-3-GMT-tranfected ASCs to iCPs of $23 \%$.

\section{iCPs integrate into host myocardium and are retained in greater numbers than stem cell transplants}

CM-DiI is a persistent, fluorescent membrane dye used to track labeled human cells that integrate into the myocardium following transplantation. ${ }^{37}$ Significantly more cells were found distributed through hearts receiving iCPs compared to those receiving ASCs $(P<0.05)$ or $\mathrm{CD} 34^{+} \mathrm{Lin}^{\text {neg }} \mathrm{BM}$ cells $(P<0.01)$. No significant difference was found in the number of transplanted cells retained in hearts receiving ASCs or BM-derived stem cells (Figure 6).

\section{iCPs show improved cardioprotective potential in vivo}

The percentage of LVFS was significantly improved in all recipients receiving stem cell or iCP samples compared to the control LAD-infarcted cohort that received only PBS $(P<0.001)$. No significant difference in LVFS was found between hearts receiving ASC samples compared to BM-derived stem cell samples. However, hearts receiving iCPs showed significantly higher endpoint LVFS compared to those receiving ASCs $(P<0.05)$ or BM-derived stem cells $(P<0.01)$ (Figure 7).

Recipients of stem cell or iCP samples showed improved remodeling compared to those in the control group, as illustrated by representative Masson's Trichrome stains (Figure 8A). Recipients of CD $34^{+} \mathrm{Lin}^{\text {neg }} \mathrm{BM}$ cells $(P<0.001)$, ASCs $(P<0.01)$, or iCP samples $(P<0.001)$ samples showed a significant reduction in infarct size compared to control animals (Figure 8B). Notably, hearts receiving iCPs had significantly smaller area at risk when compared with hearts receiving transplants of ASCs $(P<0.05), \mathrm{CD}^{2} 4^{+} \mathrm{Lin}^{\text {neg }} \mathrm{BM}$ cells $(P<0.05)$, or controls $(P<0.001)$ (Figure $8 \mathrm{C})$.

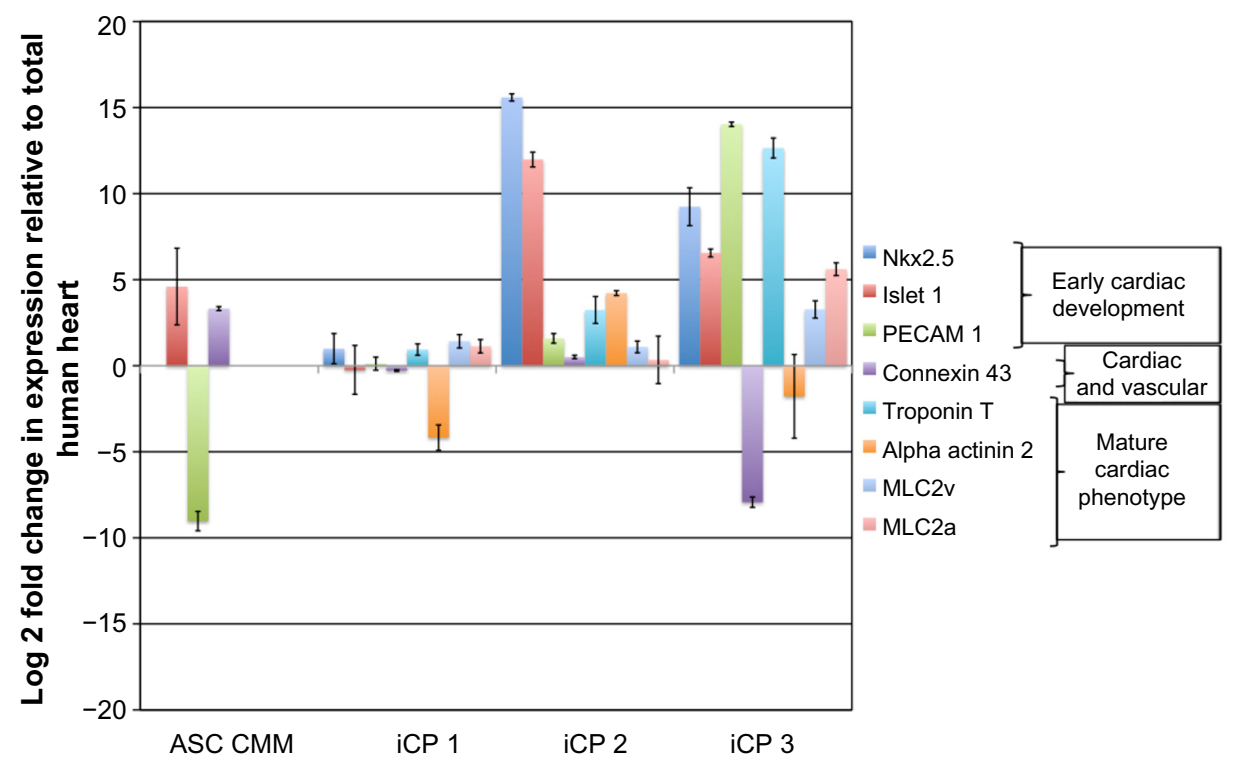

Figure 4 Quantitative RT-PCR analysis of the expression level of cardiac-specific genes relative to human heart RNA in three independent iCP lines derived from ASCs. Notes: Triplicate quantifications were performed on each gene for each iCP line derived and ASC cultured in Cardiac Myocyte Medium (ASC CMM). The developmental phase of the expression of these genes is categorized in the figure legend to the right. Expression of early cardiac marker Nkx2.5 and mature cardiac markers Troponin $\mathrm{T}$ and Myosin light chains (atrial and ventricular) was absent in ASC CMM and high in all iCP cells.

Abbreviations: RT-PCR, real-time polymerase chain reaction; iCP, induced cardiac-like progenitor; ASC, adipose-derived stem cell. 

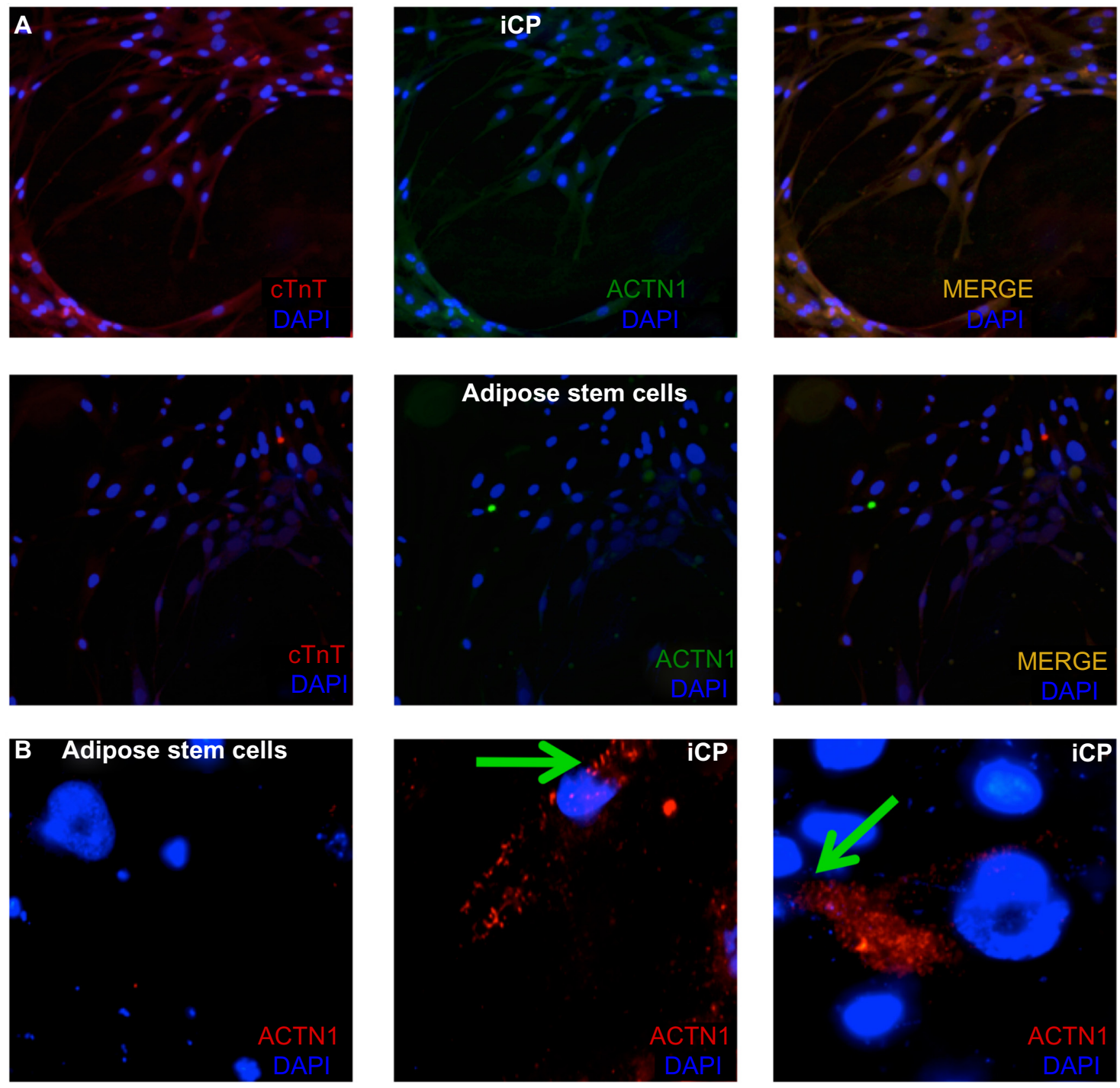

Figure 5 Analysis of cardiac-specific protein expression in iCPs.

Notes: The majority of programmed cells show the presence of troponin T (red) and $\alpha$-actinin (green). ASCs not exposed to pmGENIE-3-GMT but maintained in the same medium do not express these proteins (A). iCP cells showed sarcomeric banding in $\alpha$-actinin (red), indicated by arrows (B). Abbreviations: iCPs, induced cardiac-like progenitors; ASCs, adipose-derived stem cells; GMT, GATA4, MEF2C, and TBX5.

Periinfarct capillary density was seen to progressively increase from controls to hearts receiving $\mathrm{CD} 34^{+} \mathrm{Lin}^{\text {neg }} \mathrm{BM}$ cells, ASCs, and iCPs in a fashion similar to the decrease in area at risk (Figure 9A). A significant difference was found in capillary density between each group of hearts $(P<0.01)$, except those hearts receiving iCPs when compared with the hearts that received ASCs alone (Figure 9B).

\section{Discussion}

We have demonstrated efficient programming of human ASCs toward the cardiac lineage with three defined factors introduced by the transposase-mediated expression vector $\mathrm{p} m$ GENIE-3-GMT. The reprogrammed cells, iCPs, show altered morphology, elevated transcription of cardiac lineage-specific genes, and expression of $\alpha$-actinin and troponin $\mathrm{T}$ proteins with sarcomeric structure. Furthermore, when applied in vivo to a mouse model of myocardial infarction, these iCPs demonstrated improved functional outcomes, LVEF, and fractional shortening that correlated with a reduced area at risk when compared to treatments of ASCs or BM-derived stem cell samples. The iCPs showed increased persistence in the myocardium of recipient hearts, and ASC and iCP transplant recipients showed significantly increased capillary density within zones of infarction.

BM has received considerable attention for its potential in stem cell therapy of myocardial infarction. BM-derived stem cells especially have been targeted for potential therapeutic research because of their well characterized phenotype and ease of isolation following mobilization to the blood. However, to date, results of clinical trials using autologous 
A

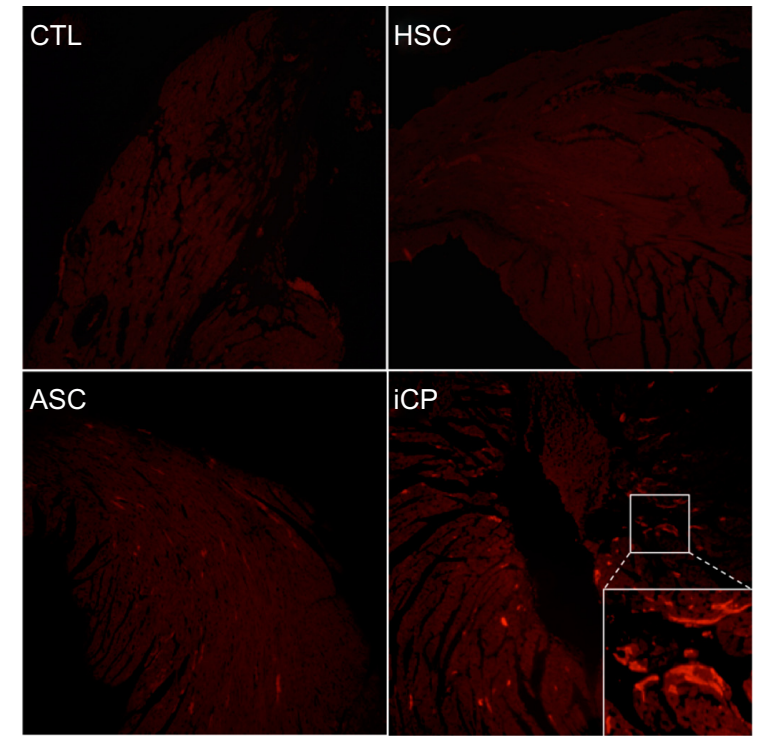

B

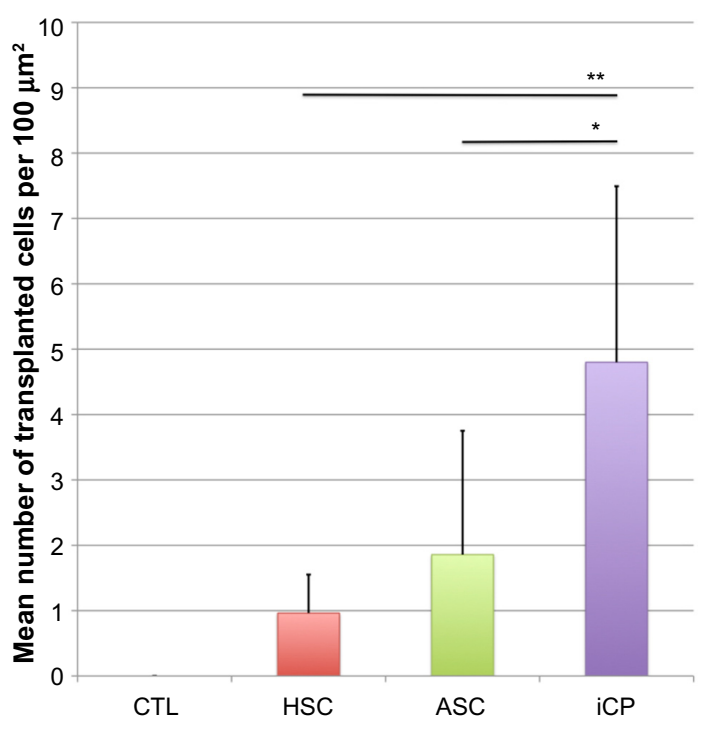

Figure 6 Analysis of the retention of transplanted cells.

Notes: Representative fluorescent images of midsections of hearts 30 days after infarction with high-objective inset showing iCP cells engrafted into the myocardium (A). Cell retention was quantified by random quadrant counting of CM-Dil-labeled cells in the host myocardium. Significantly more cells were retained in iCPs-receiving hearts compared to hearts receiving CD34 ${ }^{+} \mathrm{Lin}^{\mathrm{Neg}}$ cells $(\mathrm{HSC})(* * P<0.0 \mathrm{I})$, or ASCs $(* P<0.05)$. There was no difference between hearts receiving BM-derived stem cells or ASCs (B) (control (CTL) n=5; HSC n=8; ASCs n=7; iCPs n=9).

Abbreviations: iCP, induced cardiac-like progenitor; HSC, hematopoietic stem cell; BM, bone marrow; ASCs, adipose-derived stem cells; CTL, control.

BM stem cell samples to treat myocardial infarcts have been modest at best. ${ }^{9}$ With the effectiveness of transcoronary or intramyocardial cell injection and the timing of intervention well mapped, it has been suggested that the time has come to pursue options with potentially greater efficacy. ${ }^{38}$ ASCs have a number of advantages over BM-derived stem cells, including the relative high abundance per unit volume of tissue, the extensive proliferative capacity in vitro, and the multipotent differentiation capacity. ${ }^{4,39}$ We previously demonstrated that despite their restricted lineage fate, human $\mathrm{CD} 34^{+} \mathrm{Lin}^{\text {neg }}$ cells significantly enhance repair in a murine model of induced myocardial infarct. ${ }^{11}$ To further investigate the efficacy of stem cell therapies, in this study, we chose to compare the repair capacity of human ASCs to that of BM-derived $\mathrm{CD} 34^{+} \mathrm{Lin}^{\text {neg }}$ cells. The results presented here show that the effect of minimally processed ASCs on cardiac function and infarct size are indistinguishable from those of

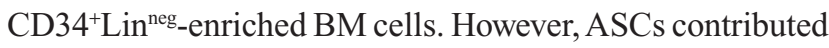
to a greater increase in vascular density around the infarction than BM-derived stem cells, making ASCs a more attractive option for intervention. Furthermore, by employing the Icellator Cell Isolation System to isolate autologous ASCs within the operating theater, it may be possible to increase the availability of point-of-care cell therapy. This would greatly reduce stress to the patient by eliminating the need for additional invasive medical procedures, as are required for isolation of $\mathrm{CD} 34^{+} \mathrm{Lin}^{\text {neg }}$ stem cells.
Another logical step to improve the outcomes of cellular therapy is to transplant cells that can replace those lost during an ischemic event and seamlessly integrate into the host myocardium, thus providing long-term gains in cardiac function. Recently, cardiac-resident progenitor cells have been discovered and associated with the potential for cardiac

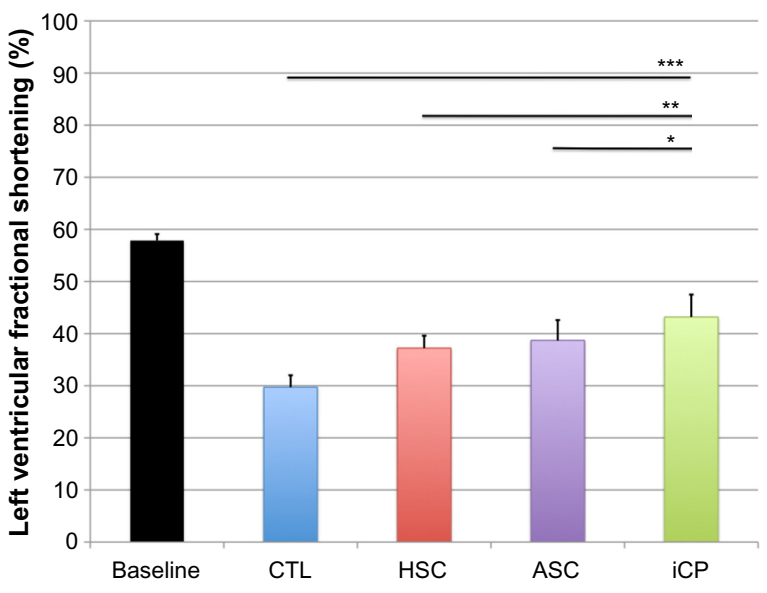

Figure 7 Analysis of the effect of iCP transplantation on cardiac function by echocardiography.

Notes: Significantly higher LVFS was observed in animals receiving cellular therapy compared to untreated control animals $(C T L)(* * * P<0.00 \mathrm{I})$. Animals receiving iCPs had significantly higher LVFS than those receiving CD $34^{+} \mathrm{Lin}^{\text {neg }}$ cells (HSC) $(* * P<0.01)$ or ASCs alone $(* P<0.05)$, with no difference found between the latter two groups. All analyses were performed I month posttransplant (CTL $n=5$; HSC $n=8$; ASCs $n=7 ;$ iCPs $n=9$ ).

Abbreviations: $\mathrm{iCP}$, induced cardiac-like progenitor; LVFS, left ventricular fractional shortening; CTL, control; HSC, hematopoietic stem cell; ASCs, adiposederived stem cells. 


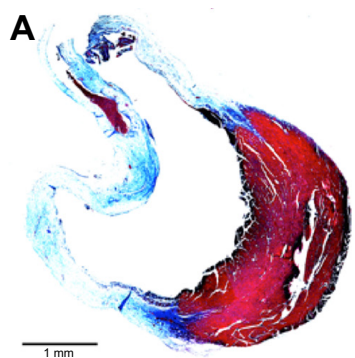

CTL

B

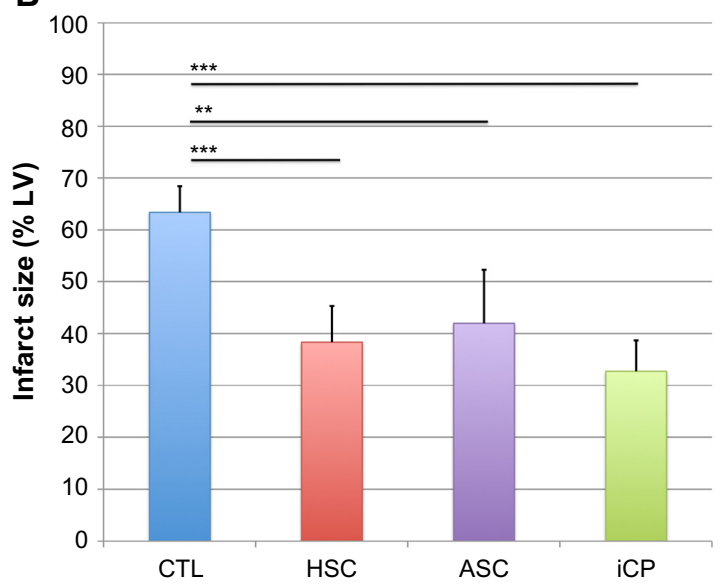

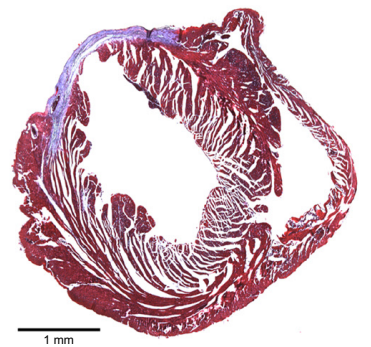

HSC

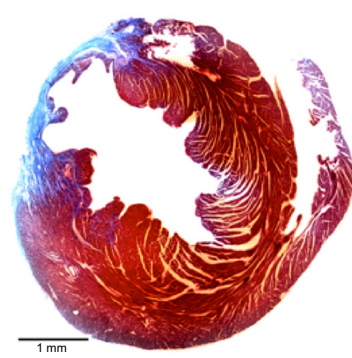

ASC

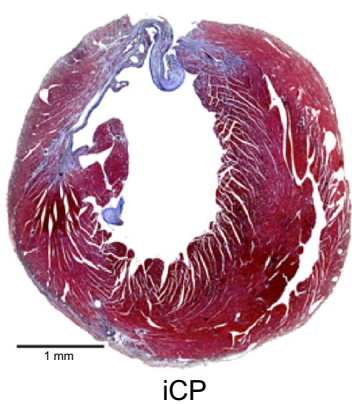

iCP

C

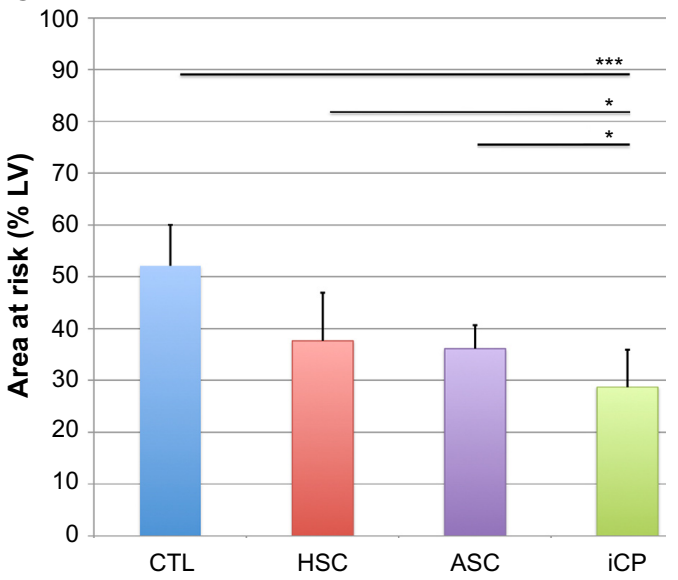

Figure 8 Analysis of the effect of $\mathrm{CP}$ transplantation on remodeling of the left ventricle.

Notes: Representative images of Masson's Trichrome staining of hearts from each group in the study demonstrating a reduction in untoward remodeling of hearts receiving cell transplants compared with control hearts (CTL) (A). Morphometric analysis of the effect of iCPs on infarct recovery showed animals receiving cell transplants had a significantly smaller circumferential infarct size than control animals $(* * * P<0.001$; $* * P<0.01)$; however, no significant difference in infarct size was observed between hearts receiving different cell transplants (B). Hearts receiving $\mathrm{ICP}$ transplants had significantly smaller areas at risk in the left ventricle compared with control hearts $(* * * P<0.00 \mathrm{I})$

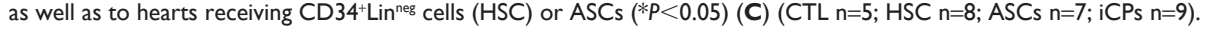

Abbreviations: iCPs, induced cardiac-like progenitors; CTL, control; HSC, hematopoietic stem cell; ASCs, adipose-derived stem cells.
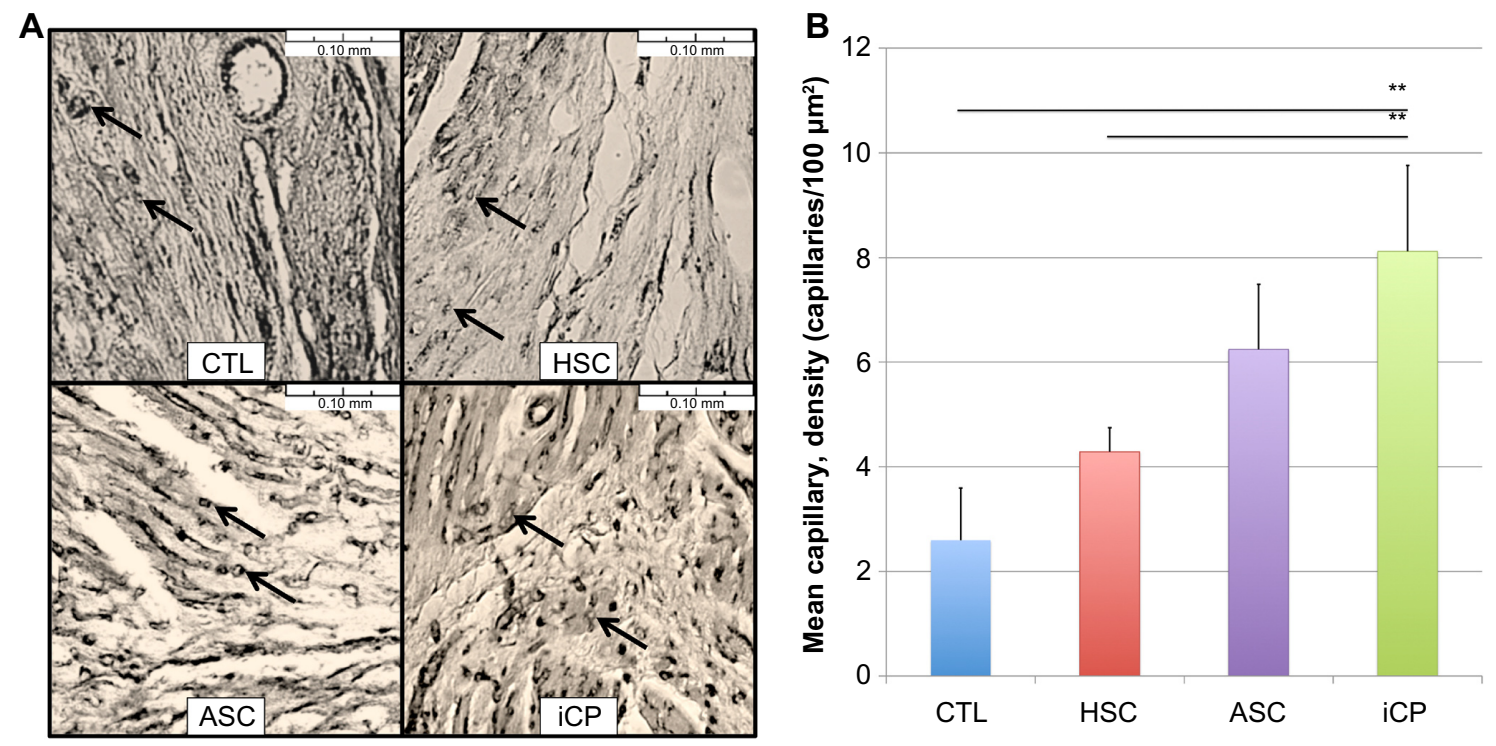

Figure 9 Analysis of the effect of iCPs on periinfarct capillary density.

Notes: Representative images of isolectin B4 staining showing the variation in capillary density between treatment groups; arrows indicate example capillaries (A). A significantly higher density was observed in all hearts receiving cells compared with controls $(C T L)(* * P<0.01)$, and in hearts receiving iCPs or ASCs compared with CD34 ${ }^{+}$Lin ${ }^{\text {neg }}$ cells $(H S C)(P<0.001$ and $P<0.01$, respectively). No difference in density was found between animals receiving iCPs or $A S C s$ alone $(B)(C T L n=5 ; H S C n=8$; ASCs $\mathrm{n}=7$; iCPs $\mathrm{n}=9$ ).

Abbreviations: iCPs, induced cardiac-like progenitors; CTL, control; ASCs, adipose-derived stem cells; HSC, hematopoietic stem cell. 
regeneration. ${ }^{40,41}$ However, in light of the low abundance of these cells and significantly invasive procedures required for isolation, the utility of these cells is uncertain at best. The advent of iPSC technology has allowed for large quantities of cardiomyocytes to be generated with a patient's own cells..$^{42}$ The directed differentiation of iPSCs into cardiomyocytes can be efficient, ${ }^{42}$ but the initial reprogramming of fibroblasts and expansion of the derived iPSCs are a slow and inefficient process. Despite their potential, iPSC-derived cardiomyocytes do not yet offer a viable therapeutic route since remodeling of a patient's infarcted heart would already have taken place by the time the cells were ready for transplantation. In contrast, reprogramming of autologous cells that are available in sufficient number and have the capacity for expansion without loss of stem cell capacity may prove to be a more attractive possibility. ${ }^{43}$

Although transposon vectors have previously been used to reprogram cells from terminal differentiation back to pluripotency, ${ }^{23,44}$ to our knowledge this is the first study demonstrating the directed differentiation of stem cells using a transposon vector. The piggyBac transposase used in this study has been shown to produce iPSCs at higher efficiencies than another transposase system, Sleeping Beauty. ${ }^{44}$ iPSCs present the exciting possibility of treating disorders with patient-specific cells that would experience no transplant rejection. For example, with the goal of addressing neurodegenerative disorders, piggyBac-and Sleeping Beauty-derived iPSCs have been differentiated into neurons and neural progenitor cells ${ }^{45,46}$ with similar results relative to embryonic stem cell-derived neural progenitors. Transposon vectors were originally designed for gene therapy; their ability to integrate large gene cassettes into the host genome and the fact that piggyBac has been shown to have less of a tendency to integrate into genes, ${ }^{35}$ make them desirable for autologous transplant applications. For example, Sleeping Beauty and piggyBac were shown to safely and stably integrate a transgene into $\mathrm{CD} 34^{+} \mathrm{HSCs}$ and maintain expression of the transgene in multiple-lineage progeny of those cells following in vivo transplantation, ${ }^{24,47}$ thus offering a route for the treatment of BM disorders. In vivo application of piggyBac has been demonstrated by the production of transgenic animals following cytoplasmic injection of the plasmid ${ }^{25}$ and the stimulation of angiogenesis in adult rat hearts by the targeted delivery of thymosin $\beta 4$ in a piggyBac cassette. ${ }^{48}$

In this study, we integrated cardiac lineage transcription factors GATA4, MEF2C, and TBX5, previously shown to convert neonatal murine cardiac fibroblasts to cardiomyocyte-like cells, ${ }^{29}$ into human adult ASCs using piggyBac.
Abundant ASCs are readily available for autologous transplantation and have the potential to differentiate into cells with cardiac cell features at low efficiency when exposed to the DNA demethylating agent 5 -azacytidine. ${ }^{49,50}$ The iCP cells derived from ASCs here express a battery of cardiac-specific markers and presented myofibril striations. Variation in the expression of cardiac markers between the iCP lines may be the result of differences in p $m$ GENIE-3GMT integration (Figure S1). GMT was previously shown to be insufficient to reprogram adult human fibroblasts toward the cardiac phenotype, ${ }^{34}$ and greater efficiencies of reprogramming are achieved with multiple factors in less developmentally mature cells. ${ }^{32} \mathrm{We}$ speculate that the greater differentiation potential of ASC compared to fibroblasts permitted the successful reprogramming observed here when using only three factors for reprogramming. Furthermore, iCPs had greater retention in the myocardium of recipient hearts than ASCs alone and induced greater functional and cardioprotective outcomes than stem cell or control treatments.

Ieda et al found that complete conversion prior to transplantation was not necessary for successful integration of the induced mouse cardiomyocytes. ${ }^{29}$ Given that the cardiac environment provides the appropriate physical, biochemical, electrical, and mechanical cues for cells undergoing differentiation to the cardiac myocyte phenotype, it may prove better to transplant cells before they completely reprogram. ASCs have been shown to develop into both cardiomyocytes and vascular cells in very small numbers after transplantation into the myocardium ${ }^{51}$ so it is possible that iCPs may continue to develop in vivo.

By directing the differentiation of human ASCs into iCPs and utilizing these cells in the treatment of myocardial infarction in a mouse model, we have demonstrated a method of enhancing the potential of stem cell cellular therapies for heart disease. Future development of this work could involve optimizing the programming process and footprintfree excision of the transgenes prior to reintegration of the cells into the heart using Transposagen Biopharmaceuticals, Inc.'s hyperactive piggyBac. This would reduce the ex vivo time burden and increase the ease of translation to a pointof-care therapy.

\section{Acknowledgments}

At the John A. Burns School of Medicine we would like to thank M Bellinger at the Histopathology Core; and Dr C Walton, Dr T Matsui, and N Yorichika at the Center for Cardiovascular Research for their advice and assistance. 


\section{Disclosure}

KDL has no financial stake in Tissue Genesis, Inc.; SM is the founder of Manoa BioSciences. The authors report no conflicts of interest in this work.

\section{References}

1. Rodbell M. Localization of lipoprotein lipase in fat cells of rat adipose tissue. J Biol Chem. 1964;239(3):753-755.

2. Van RL, Bayliss CE, Roncari DA. Cytological and enzymological characterization of adult human adipocyte precursors in culture. J Clin Invest. 1976;58(3):699-704.

3. Faust IM, Johnson PR, Hirsch J. Adipose tissue regeneration following lipectomy. Science. 1977;197(4301):391-393.

4. Zuk PA, Zhu M, Ashjian P, et al. Human adipose tissue is a source of multipotent stem cells. Mol Biol Cell. 2002;13(12):4279-4295.

5. Nagase T, Matsumoto D, Nagase M, et al. Neurospheres from human adipose tissue transplanted into cultured mouse embryos can contribute to craniofacial morphogenesis: a preliminary report. J Craniofacial Surg. 2007;18(1):49-53.

6. Seo MJ, Suh SY, Bae YC, Jung JS. Differentiation of human adipose stromal cells into hepatic lineage in vitro and in vivo. Biochem Biophys Res Commun. 2005;328(1):258-264.

7. McIntosh K, Zvonic S, Garrett S, et al. The immunogenicity of human adipose-derived cells: temporal changes in vitro. Stem Cells. 2006;24(5):1246-1253.

8. Arnous S, Mozid A, Martin J, Mathur A. Bone marrow mononuclear cells and acute myocardial infarction. Stem Cell Res Ther. 2012;3(1):2.

9. Delewi R, Andriessen A, Tijssen JGP, Zijlstra F, Piek JJ, Hirsch A. Impact of intracoronary cell therapy on left ventricular function in the setting of acute myocardial infarction: a meta-analysis of randomised controlled clinical trials. Heart. 2013;99(4):225-232.

10. Uemura R, Xu M, Ahmad N, Ashraf M. Bone marrow stem cells prevent left ventricular remodeling of ischemic heart through paracrine signaling. Circ Res. 2006;98(11):1414-1421.

11. Davy P, Walker B, Wong L, Allsopp R. Hematopoietic stem cells are a critical sub-population of whole bone marrow in the treatment of myocardial infarction. Stem Cell Discov. 2013;03(02):117-126.

12. Iwasaki H, Kawamoto A, Ishikawa M, et al. Dose-dependent contribution of CD34-positive cell transplantation to concurrent vasculogenesis and cardiomyogenesis for functional regenerative recovery after myocardial infarction. Circulation. 2006;113(10):1311-1325.

13. Quyyumi AA, Waller EK, Murrow J, et al. CD34(+) cell infusion after ST elevation myocardial infarction is associated with improved perfusion and is dose dependent. Am Heart J. 2011;161(1):98-105.

14. Bai X, Yan Y, Song YH, et al. Both cultured and freshly isolated adipose tissue-derived stem cells enhance cardiac function after acute myocardial infarction. Eur Heart J. 2010;31(4):489-501.

15. Cai L, Johnstone BH, Cook TG, et al. IFATS collection: human adipose tissue-derived stem cells induce angiogenesis and nerve sprouting following myocardial infarction, in conjunction with potent preservation of cardiac function. Stem Cells. 2009;27(1):230-237.

16. Danoviz ME, Nakamuta JS, Marques FL, et al. Rat adipose tissue-derived stem cells transplantation attenuates cardiac dysfunction post infarction and biopolymers enhance cell retention. PLoS One. 2010;5(8):e12077.

17. Imanishi $\mathrm{Y}$, Miyagawa S, Maeda N, et al. Induced adipocyte cell-sheet ameliorates cardiac dysfunction in a mouse myocardial infarction model a novel drug delivery system for heart failure. Circulation. 2011;124 (11 Suppl 1):S10-S17.

18. Valina C, Pinkernell K, Song YH, et al. Intracoronary administration of autologous adipose tissue-derived stem cells improves left ventricular function, perfusion, and remodelling after acute myocardial infarction. Eur Heart J. 2007;28(21):2667-2677.

19. Rehman J. Secretion of angiogenic and antiapoptotic factors by human adipose stromal cells. Circulation. 2004;109(10):1292-1298.
20. Hsiao ST, Asgari A, Lokmic Z, et al. Comparative analysis of paracrine factor expression in human adult mesenchymal stem cells derived from bone marrow, adipose, and dermal tissue. Stem Cells Dev. 2012;21(12):2189-2203.

21. Houtgraaf JH, den Dekker WK, van Dalen BM, et al. First experience in humans using adipose tissue-derived regenerative cells in the treatment of patients with ST-segment elevation myocardial infarction. J Am Coll Cardiol. 2012;59(5):539-540.

22. Wu SC, Meir YJ, Coates CJ, et al. piggyBac is a flexible and highly active transposon as compared to Sleeping Beauty, Tol2, and Mos 1 in mammalian cells. Proc Natl Acad Sci US A. 2006;103(41):15008-15013.

23. Kaji K, Norrby K, Paca A, Mileikovsky M, Mohseni P, Woltjen K. Virus-free induction of pluripotency and subsequent excision of reprogramming factors. Nature. 2009;458(7239):771-775.

24. Hollis RP, Nightingale SJ, Wang X, et al. Stable gene transfer to human CD34+ hematopoietic cells using the Sleeping Beauty transposon. Exp Hematol. 2006;34(10):1333-1343.

25. Li Z, Zeng F, Meng F, et al. Generation of transgenic pigs by cytoplasmic injection of piggyBac transposase based pmGENIE-3 plasmids. Biol Reprod. 2014;90(5):93.

26. Takahashi K, Yamanaka S. Induction of pluripotent stem cells from mouse embryonic and adult fibroblast cultures by defined factors. Cell. 2006;126(4):663-676.

27. Takeuchi JK, Bruneau BG. Directed transdifferentiation of mouse mesoderm to heart tissue by defined factors. Nature. 2009;459(7247): 708-711.

28. Efe JA, Hilcove S, Kim J, et al. Conversion of mouse fibroblasts into cardiomyocytes using a direct reprogramming strategy. Nat Cell Biol. 2011;13(3):215-222.

29. Ieda M, Fu JD, Delgado-Olguin P, et al. Direct reprogramming of fibroblasts into functional cardiomyocytes by defined factors. Cell. 2010;142(3):375-386.

30. Owens JB, Urschitz J, Stoytchev I, et al. Chimeric piggyBac transposases for genomic targeting in human cells. Nucleic Acids Res. 2012;40(14):6978-6991.

31. Tang XL, Rokosh G, Sanganalmath SK, et al. Intracoronary administration of cardiac progenitor cells alleviates left ventricular dysfunction in rats with a 30-day old infarction. Circulation. 2010;121(2):293.

32. Song K, Nam YJ, Luo X, et al. Heart repair by reprogramming nonmyocytes with cardiac transcription factors. Nature. 2012;485(7400): 599-604.

33. Nam YJ, Song K, Luo X, et al. Reprogramming of human fibroblasts toward a cardiac fate. Proc Natl Acad Sci U S A. 2013;110(14): 5588-5593.

34. Wada R, Muraoka N, Inagawa $\mathrm{K}$, et al. Induction of human cardiomyocyte-like cells from fibroblasts by defined factors. Proc Natl Acad Sci US A. 2013;110(31):12667-12672.

35. Fu JD, Stone NR, Liu L, et al. Direct reprogramming of human fibroblasts toward a cardiomyocyte-like state. Stem Cell Rep. 2013;1(3): 235-247.

36. Kondo RP, Dederko DA, Teutsch C, et al. Comparison of contraction and calcium handling between right and left ventricular myocytes from adult mouse heart: a role for repolarization waveform. $J$ Physiol. 2006;571(1):131-146.

37. Bartunek J, Croissant JD, Wijns W, et al. Pretreatment of adult bone marrow mesenchymal stem cells with cardiomyogenic growth factors and repair of the chronically infarcted myocardium. Am J Physiol Heart Circ Physiol. 2007;292(2):H1095-H1104.

38. Raynaud CM, Yacoub MH. Clinical trials of bone marrow derived cells for ischemic heart failure. Time to move on? TIME, SWISS-AMI, CELLWAVE, POSEIDON and C-CURE. Glob Cardiol Sci Pract. 2013;2013(3):28.

39. Zhu Y, Liu T, Song K, Fan X, Ma X, Cui Z. Adipose-derived stem cell: a better stem cell than BMSC. Cell Biochem Funct. 2008;26(6):664-675.

40. He J-Q, Vu DM, Hunt G, Chugh A, Bhatnagar A, Bolli R. Human cardiac stem cells isolated from atrial appendages stably express c-kit. PLoS One. 2011;6(11):e27719. 
41. Urbanek K, Torella D, Sheikh F, et al. Myocardial regeneration by activation of multipotent cardiac stem cells in ischemic heart failure. Proc Natl Acad Sci U S A. 2005;102(24):8692-8697.

42. Lian X, Hsiao C, Wilson G, et al. Robust cardiomyocyte differentiation from human pluripotent stem cells via temporal modulation of canonical Wnt signaling. Proc Natl Acad Sci U S A. 2012;109(27):E1848-E1857.

43. Chong JJ, Yang X, Don CW, et al. Human embryonic-stem-cellderived cardiomyocytes regenerate non-human primate hearts. Nature. 2014;510(7504):273-277.

44. Talluri TR, Kumar D, Glage S, et al. Non-viral reprogramming of fibroblasts into induced pluripotent stem cells by Sleeping Beauty and piggyBac transposons. Biochem Biophys Res Commun. 2014;450(1):581-587.

45. Salewski RP, Buttigieg J, Mitchell RA, van der Kooy D, Nagy A, Fehlings MG. The generation of definitive neural stem cells from PiggyBac transposon-induced pluripotent stem cells can be enhanced by induction of the notch signaling pathway. Stem Cells Dev. 2013;22(3):383-396.

46. Klincumhom N, Pirity MK, Berzsenyi S, et al. Generation of neuronal progenitor cells and neurons from mouse sleeping beauty transposongenerated induced pluripotent stem cells. Cell Reprogramming. 2012;14(5):390-397.
47. Xue X, Huang X, Nodland SE, et al. Stable gene transfer and expression in cord blood-derived CD34+ hematopoietic stem and progenitor cells by a hyperactive Sleeping Beauty transposon system. Blood. 2009;114(7):1319-1330.

48. Chen S, Shimoda M, Chen J, Grayburn PA. Stimulation of adult resident cardiac progenitor cells by durable myocardial expression of thymosin beta 4 with ultrasound-targeted microbubble delivery. Gene Ther. 2013;20(2):225-233.

49. Choi YS, Dusting GJ, Stubbs S, et al. Differentiation of human adiposederived stem cells into beating cardiomyocytes. J Cell Mol Med. 2010;14(4):878-889.

50. Perán M, Marchal JA, López E, et al. Human cardiac tissue induces transdifferentiation of adult stem cells towards cardiomyocytes Cytotherapy. 2010;12(3):332-337.

51. Yang JJ, Liu ZQ, Zhang JM, et al. Real-time tracking of adipose tissuederived stem cells with injectable scaffolds in the infarcted heart. Heart Vessels. 2013;28(3):385-396. 


\section{Supplementary materials}

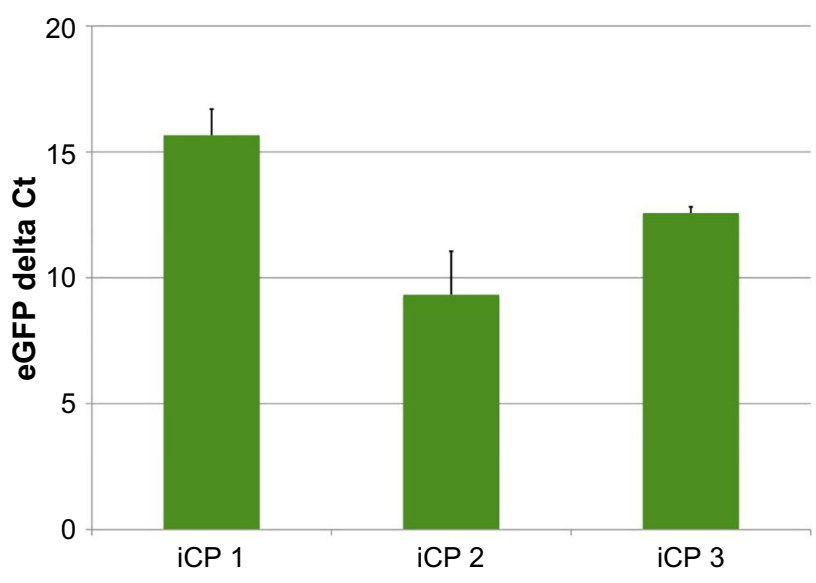

Figure SI Analysis of eGFP expression in iCP lines 14 days after transfection. Notes: Expression of eGFP mRNA in iCP lines I-3 showed variability 14 days after transfection with pmGENIE-3-GMT. Normalized mean $\mathrm{Ct}$ values for triplicate reactions are displayed for each $\mathrm{ICP}$ line.

Abbreviations: iCP, induced cardiac-like progenitor; GMT, Gata4, Mef2c, and Tbx5; eGFP, enhanced green fluorescent protein.
Video SI iCP cell contracting under electrical stimulation.

Notes: iCP cell exhibiting sacromeric changes when stimulated with $40 \mathrm{~V}$ at a frequency of $2 \mathrm{~Hz}$, contractions are arrested in the final 3 seconds when electrical stimulation is removed. Partial anchoring of the cell to the matrix substrate has resulted in some atypical movement.

Abbreviation: iCP, induced cardiac-like progenitor.

\section{Publish your work in this journal}

Stem Cells and Cloning: Advances and Applications is an international, peer-reviewed, open access journal. Areas of interest in stem cell research include: Embryonic stem cells; Adult stem cells; Blastocysts; Cordblood stem cells; Stem cell transformation and culture; Therapeutic cloning; Umbilical cord blood and bone marrow cells; Laboratory, animal and human therapeutic studies; Philosophical and ethical issues related to stem cell research. This journal is indexed on CAS. The manuscript management system is completely online and includes a quick and fair peer-review system. Visit http://www.dovepress.com/ testimonials.php to read real quotes from published authors. 